\title{
Parides panthonus jaguarae (Foetterle) (Lepidoptera, Papilionidae) redescoberto em Minas Gerais, Brasil: sua identidade ${ }^{1}$
}

\author{
Olaf H. H. Mielke ${ }^{2}$, Carlos Guilherme C. Mielke ${ }^{2,3}$ \& Mirna M. Casagrande ${ }^{2}$ \\ ${ }^{1}$ Contribuição número 1184 do Departamento de Zoologia, Universidade Federal do Paraná. \\ 2 Laboratório de Estudos de Lepidoptera Neotropical, Departamento de Zoologia, Setor de Ciências Biológicas, Universidade \\ Federal do Paraná. Caixa Postal 19020, 81531-980 Curitiba, Paraná, Brasil. Pesquisador do CNPq. E-mail: omhesp@ufpr.br; \\ mibras@ufpr.br \\ ${ }^{3}$ Caixa Postal 1206, 84145-000 Carambeí, Paraná, Brasil. E-mail: cmielke1@uol.com.br
}

\begin{abstract}
Parides panthonus jaguarae (Foetterle) (Lepidoptera, Papilionidae) rediscovered in Minas Gerais, Brazil: his identity. Parides panthonus jaguarae (Foetterle, 1902) was rediscovered at Brumadinho, Minas Gerais and is synomyzised with Parides burchellanus (Westwood, 1872) syn. nov. The first is the male of the second. KEY WORDS. Parides burchellanus, Neotropical, sistematics.
\end{abstract}

RESUMO. Parides panthonus jaguarae (Foetterle,1902) foi redescoberto em Brumadinho, Minas Gerais e é sinonimizado com Parides burchellanus (Westwood, 1872) syn. nov. A primeira é o macho da segunda.

PALAVRAS CHAVE. Parides burchellanus, neotropical, sistemática.

Os Papilionidae sempre foram os lepidópteros muito estimados pelos lepidopterólogos, razão de constituirem um dos grupos mais bem conhecidos entre as borboletas. A maioria das espécies é bastante comum e de distribuição ampla, enquanto outras são extremamente localizadas.

Na última revisão da família (Tyler et al. 1994), Parides panthonus jaguarae (Foetterle, 1902) é mencionada como uma espécie rara e não vista nos últimos 70 anos; provavelmente até desde a sua descrição. Na descrição original são mencionados cinco exemplares masculinos procedentes da Fazenda Jaguara, próximo do Rio das Velhas, Minas Gerais e de Batatais, São Paulo. Esta espécie, assim como Parides burchellanus (Westwood, 1872), está na lista de espécies ameaçadas de Minas Gerais (Casagrande et al. 1998; Brown Jr. \& Mielke 1998) e na "Lista nacional das espécies da fauna brasileira ameaçadas de extinção".

Durante as últimas décadas a subespécie foi procurada, inclusive pelos autores e pelo Dr. Keith Brown Jr., em uma de suas localidades típicas mencionadas: Fazenda Jaguara, cuja sede se localiza atualmente no Município de Matosinhos, Minas Gerais e onde ainda há uma pequena mata típica de floresta atlântica, porém sem sucesso. Como a Fazenda Jaguara, na época da captura (1902) era muito maior, chegando nas proximidades de Nova Lima (informação de pessoas da própria fazenda), a localidade exata da captura dos exemplares poderia também estar nas proximidades desta cidade localizada ao lado de Belo Horizonte.
Recentemente, por indicação do Sr. Fernando Campos, idealizador e executor do "Borboletário do Jardim Botânico de Belo Horizonte", Minas Gerais, teve-se a oportunidade de conhecer o Dr. Samir Melke, um médico e colecionador autônomo de lepidópteros, em cuja coleção verificou-se a existência de um exemplar desta subespécie coletada nas proximidades de Belo Horizonte. Levados pela curiosidade para reencontrála, visitou-se o mencionado local, entre os dias 3 e 5 de janeiro de 2002. Em três dias de campo avistou-se mais de 50 exemplares, tendo então sido redescoberta uma população bastante vigorosa, com atividades de vôo entre 10:00 e 16:00 h.

A área de ocorrência é área de cerrado com pequenas matas de galeria onde a espécie voa tão somente ao longo e sobre os riachos de até alguns metros de largura e encoberto pela vegetação. Esta deve ser a razão de sua suposta raridade na natureza, pois um caminho utilizado pelos coletores normalmente não vai ao longo do riacho, e sim atravessando-o. Dificilmente deixa o leito do riacho para freqüentar flores a fim de se alimentar ou ovipositar em Arsitolochia chamissonis Duchartre (Aristolochiaceae), sua planta hospedeira descoberta e identificada pelo Sr. Fernando Campos. Ainda, de acordo com este amigo e colega que mora em Belo Horizonte e freqüentemente vai à região de sua ocorrência, a espécie ocorre praticamente o ano todo.

Após coletar alguns exemplares, recém eclodidos e outros mais velhos já bastante danificados, verificou-se inicialmente uma variação na coloração das franjas nos espaços entre as veias das asas posteriores: rosa vivo nos exemplares no- 

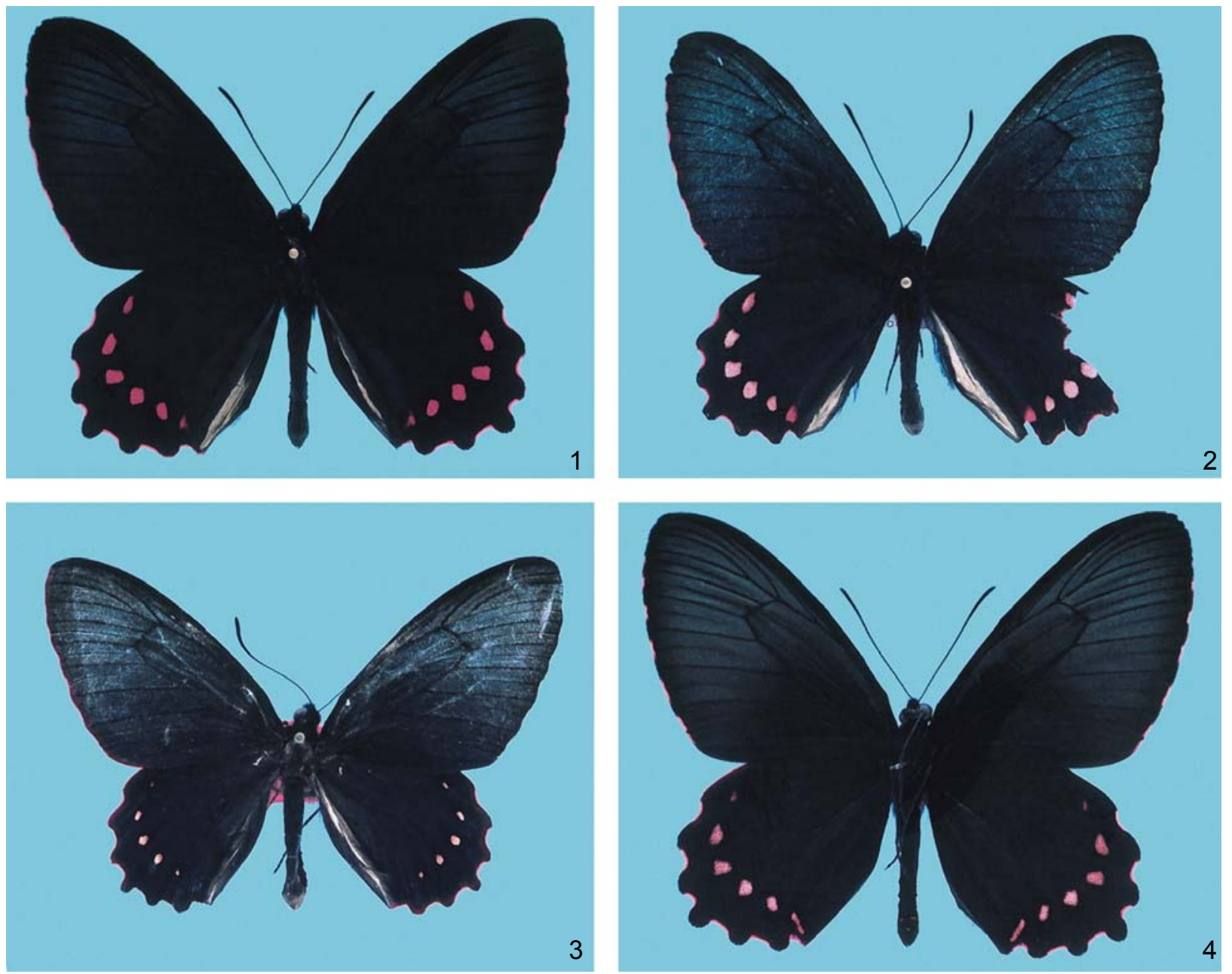

Figuras 1-4. Parides burchellanus: (1) macho, face dorsal, 5-I-2002, Casabranca, Brumadinho, Minas Gerais, 900m, O.-C. Mielke leg., exemplar recém eclodido, com franjas rosas e manchas alares rosa vivo; (2) macho, face dorsal, mesmos dados, exemplar já voado, com franjas rosas mais claras e manchas alares rosa claro; (3) macho, face dorsal, 1958, Carmo do Rio Claro, Minas Gerais, exemplar já voado, franjas brancas e manchas alares rosa claro, e reduzidas; (4) macho, face ventral, mesmo exemplar da figura 1.

vos e quanto mais velhos e danificados, de um rosa mais claro, chegando ao branco, isto tanto nos machos como nas fêmeas. Após examinar comparativamente os exemplares coletados com mais cuidado em laboratório, verificou-se que as franjas das asas posteriores são de um rosa vivo nos machos recém eclodidos e chegando ao branco em exemplares mais velhos; nas fêmeas estas franjas são brancas na parte apical e somente de um rosa vivo na parte basal, chegando ao branco em exemplares mais velhos. As franjas das asas anteriores são brancas e com poucas escamas basais rosas nos machos, e brancas nas fêmeas. Também a coloração das manchas rosas das asas posteriores é mais acentuada nos exemplares recém eclodidos que nos exemplares mais velhos, assim como o tamanho e a forma destas manchas é bastante variável (Figs 1-5).

\section{CONCLUSÃO}

Na descrição original de Papilio burchellanus, baseada em um exemplar fêmea (holótipo) procedente de Tenénte [sic], próximo de Farinha Podre (local inexistente em mapas, porém de acordo com Papavero (1973), deve estar nas cercanias de Uberaba, Minas Gerais) as franjas são mencionadas como sendo brancas, enquanto que na descrição de Papilio jaguarae, baseada em cinco exemplares machos, as franjas são mencionadas como rosas (Foetterle 1902). Tyler et. al. (1994) se utilizaram desta diferença para separar estes dois taxa: Parides panthonus jaguarae (Foetterle, 1902) e Parides burchellanus (Westwood, 1872). Como esta variação é uma simples diferença entre os sexos, considera-se as duas sinônimas (syn. nov.), 

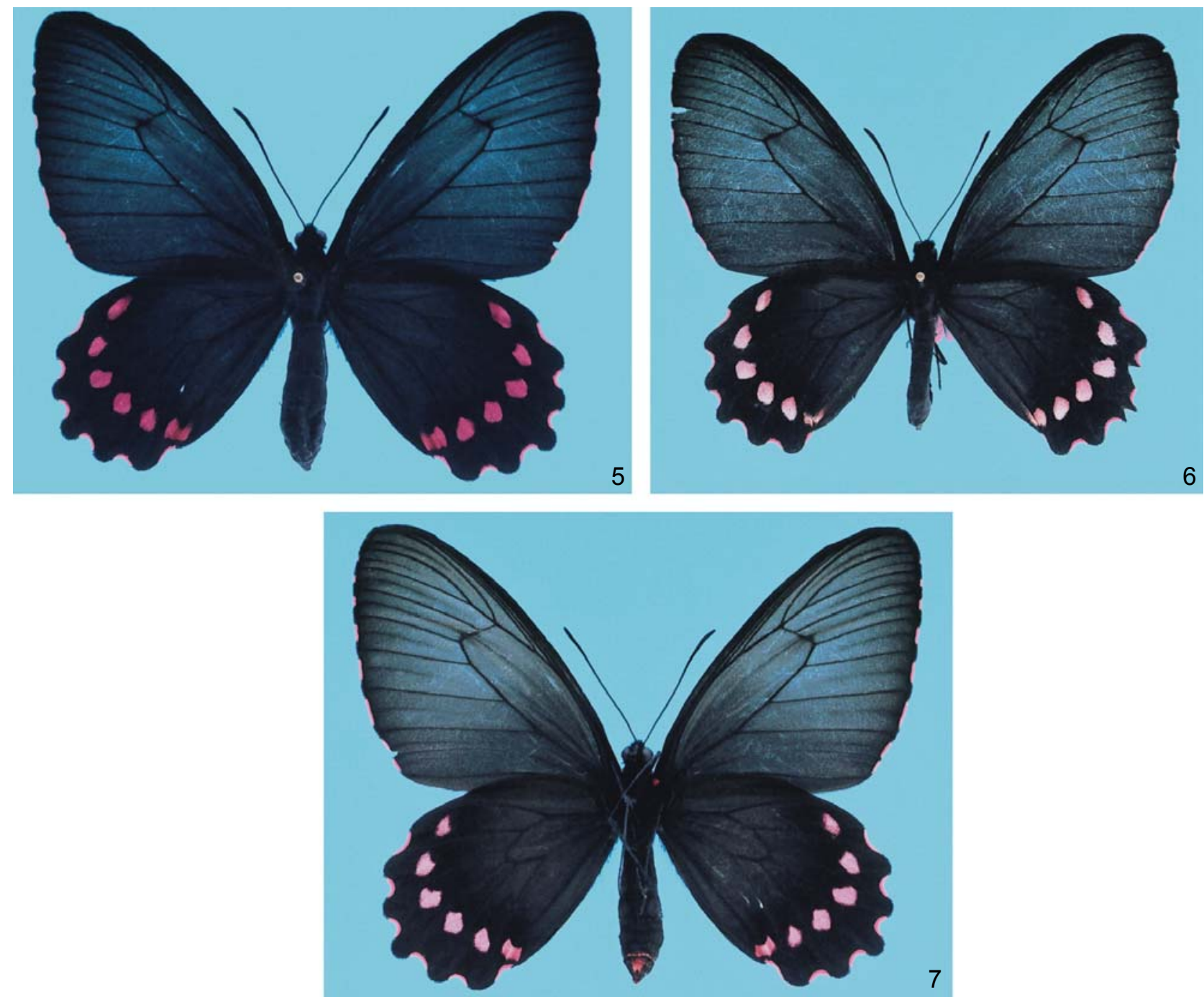

Figuras 5-7. Parides burchellanus: (5) fêmea, face dorsal, 21-IV-2003, mesma procedência do exemplar da figura 1, O. Mielke leg., exemplar recém eclodido, franjas rosas na base e brancas na parte distal e manchas alares rosa vivo; (6) fêmea, face dorsal, 5-I-2003, mesma procedência do exemplar da figura 1, exemplar já voado, franjas brancas e manchas alares rosa claro; (7) fêmea, face ventral, mesmo exemplar da figura 5.

sendo o último nome o mais antigo, logo prevalescendo sobre o anterior. A genitália dos exemplares com franjas rosas (jaguarae) e brancas (burchellanus) não diferem entre si.

Fica então a questão: se Parides burchellanus é então uma subespécie de Parides panthonus (Cramer, 1780), pois esta é muito semelhante, ocorrendo na Guiana, Suriname, Guiana Francesa e no Estado do Amapá (Brasil), ou seria uma espécie distinta. Devido às diferenças nas genitálias masculinas (Figs 8-11), ou seja, nas espessuras dos edeagos e nos formatos das harpes, optou-se por acreditar que sejam espécies distintas. Em Parides panthonus o edeago é mais curto e espesso e a harpe termina de modo aproximadamente retangular $(\mathrm{n}=1)$, enquanto que em Parides burchellanus o edeago é maior e mais delgado e a harpe termina de modo arredondada $(n=5)$ (Figs 6,7$)$; TyLer et al. (1994: 211) apresentam uma variação das harpes de P. panthonus. Mais material deve ser examinado para reavaliar as subespécies de Parides panthonus.

Parides burchellanus foi redescoberto em Casabranca, Município de Brumadinhos, Minas Gerais, uma área loteada para o estabelecimento de sítios, onde foi verificada a presença de uma população bastante numerosa. A sua planta hospedeira também é comum na beira dos riachos. Ainda é conhecida 

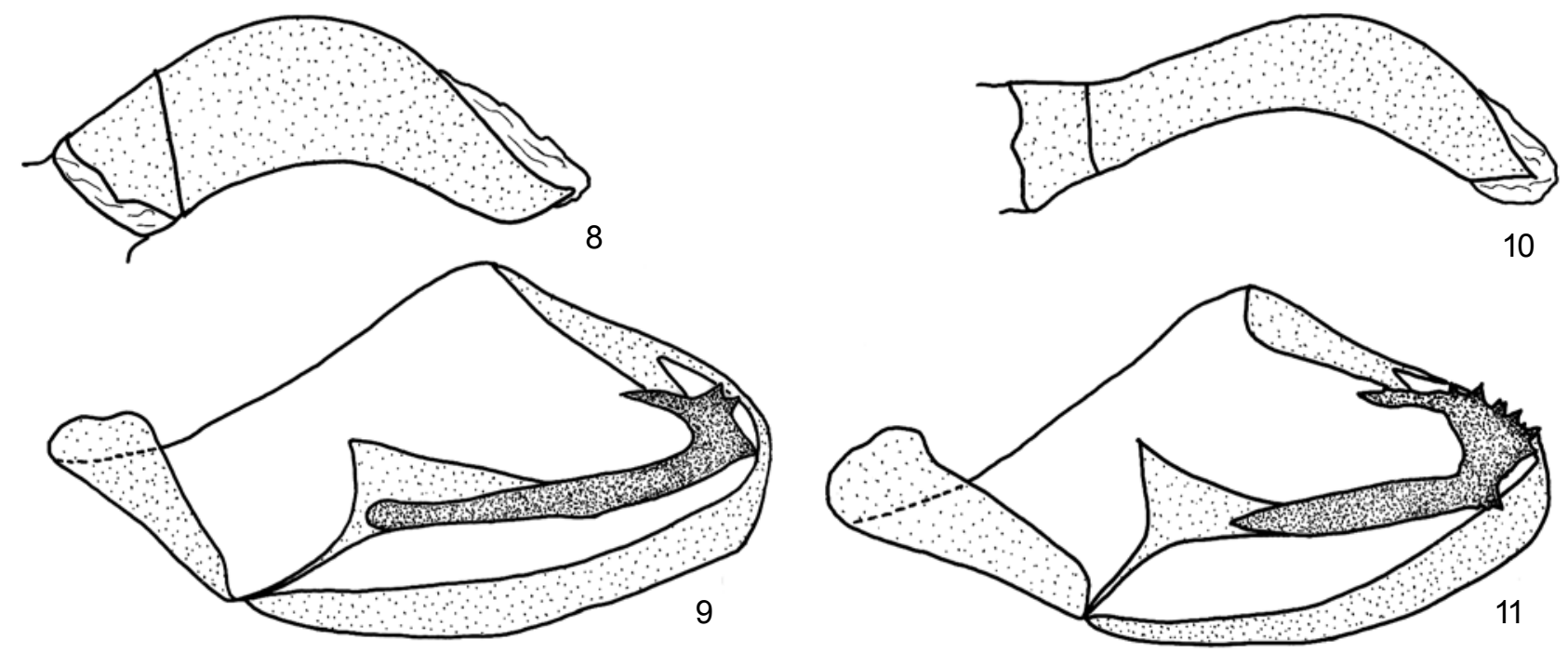

Figuras 8-11. (8-9) Parides panthonus panthonus, macho, meados XI-1959, Serra do Navio, Rio Amapari, Amapá, 100 m, H. Ebert leg., vistas (8) lateral direita do edeago e (9) interna da valva direita; (10-11) Parides burchellanus, macho, 4-I-2002, Casabranca, Brumadinho, Minas Gerais, 900 m, O.-C. Mielke leg., vistas (10) lateral direita do edeago e (11) interna da valva direita.

de algumas outras localidades, porém sem dados populacionais: Distrito Federal (Planaltina), Goiás (Planaltina), Minas Gerais (Farinha Podre, na região de Uberaba, não localizado exatamente) e São Paulo (Batatais). A localidade Casabranca, São Paulo, mencionada por Tyler et. al. (1994), Casagrande et al. (1998) é um lapso, pois esta deve ser o mesmo distrito de Brumadinho, Minas Gerais. Brown \& Mielke (1998) e Casagrande et al. (1998) ainda citam Carmo do Rio Claro (Minas Gerais), baseado em exemplares coletados por estudantes de um colégio do segundo grau da região.

Certamente a espécie ainda ocorre em muitos outros lugares entre os locais mencionados, pois é a área de ocorrência de cerrados com muitos riachos margeados por pequenas matas de galeria. A espécie foi considerada rara pela simples falta de oportunidades de trabalho de campo. Este deve ser realizado para diagnosticar a sua real distribuição geográfica e áreas devem ser preservadas para evitar um declínio das populações existentes, pois parece ser uma espécie de habitat bastante limitado, ou seja, pequenas matas de galeria no cerrado.

\section{AGRADECIMENTOS}

Agradecemos ao Sr. Fernando Campos pela ajuda no trabalho de campo, ao Dr. Samir Melke pela informação do local de ocorrência da espécie e ao CNPq pelas bolsas de produtividade e pesquisa.

\section{REFERÊNCIAS BIBLIOGRÁFICAS}

Brown Jr., K.S. \& O.H.H. Mielke. 1998. Parides panthous jaguarae (Foetterle, 1902), Parides burchellanus (Westwood, 1872), p. 512-517. In: A.B.M. Machado; G.A.B. Da Fonseca; R.B. Machado; L.M. De S. Aguiar \& L.V. Lins. Livro Vermelho das Espécies Ameaçadas de Extinção da Fauna de Minas Gerais. Belo Horizonte, Fundação Biodiversitas, 605p.

Casagrande, M.M.; O.H.H. Mielke \& K.S. Brown Jr. 1998. Borboletas (Lepidoptera) ameaçadas de extinção em Minas Gerais, Brasil. Revista Brasileira de Zoologia, Curitiba, 15 (1): 241-259.

Foetterle, J.G. 1902. Descripção de Lepidopteros novos do Brazil. Revista do Museu Paulista, São Paulo, 5: 618-652.

Papavero, N. 1973. Essays on the history on neotropical Dipterology. São Paulo, Museu de Zoologia, vol. 2, p. 218446.

Tyler, H.A.; K.S. Brown JR. \& K.H. Wilson. 1994. Swallowtail Butterflies of the Americas. A Study in Biological Dynamics, Ecological Diversity, Biosystematics, and Conservation. Gainesville, Scientific Publishers Inc., 376p.

Recebido em 28.VIII.2003; aceito em 12.I.2004. 